\title{
Mechanical Collapse Testing on Aluminum Stiffened Plate Structures for Marine Applications
}

\author{
Jeom Kee Paik ${ }^{1)}$, Celine Andrieu ${ }^{2)}$, and H. Paul Cojeen ${ }^{3)}$ \\ ${ }^{1)}$ Pusan National University, Korea, ${ }^{2)}$ Alcan Marine, France, ${ }^{3)}$ U.S. Coast Guard, USA
}

\begin{abstract}
The present paper is a summary of the $R \& D$ results obtained through SSC SR-1446 project sponsored by Ship Structure Committee together with Alcan Marine, France. It is recognized that the use of ultimate limit state (ULS) design method in addition to more conventional structural design standards will help make possible to move high speed vessels to open ocean transiting of very large high speed vessels, which is what the US Navy is certainly trying to do.

The aim of the project is to investigate the collapse characteristics of aluminum stiffened plate structures used for marine applications by mechanical testing, together with nonlinear FEA. Fabrication related initial imperfections significantly affect the ULS behavior, and thus it is of vital importance to identify the features of initial imperfections prior to ULS computations. In the present study, statistical database of fabrication related initial imperfections on welded aluminum stiffened plate structures is also developed. The database and insights developed will be very useful for design and building of welded aluminum high-speed ocean-going vessel structures.
\end{abstract}

\section{Keywords}

Aluminum stiffened plate structures; High-speed oceangoing vessels; Ultimate limit state design; Mechanical collapse testing; Fabrication related initial imperfections; Nonlinear finite element analysis.

\section{Introduction}

The use of high strength aluminum alloys in shipbuilding provides many benefits but also presents many challenges. The benefits of using aluminum versus steel include lighter weight, which helps increase cargo capacity and/or reduce power requirements, excellent corrosion resistance and low maintenance. Challenges include reduced stiffness causing greater sensitivity to deformation, buckling, and plastic collapse and different welding practices.

The benefits noted above are now well recognized, particularly for the design and construction of war ships, littoral surface crafts, and littoral combat ships as well as fast passenger ships. The size of such ships is increasing, causing various related design challenges compared to vessels with shorter length. In addition to aluminum alloys being less stiff than mild steel, no refined ultimate limit state (ULS) design methods involving local and overall ULS assessment exist unlike steel structures where the necessary information is plentiful. The use of ULS design method in addition to more conventional structural design standards will be able to help design and build very large ocean-going aluminum high speed vessel structures.

The present paper is a summary of the $R \& D$ results obtained through SSC SR-1446 project sponsored by Ship Structure Committee together with Alcan Marine, France. Buckling collapse characteristics of welded aluminum stiffened plate structures were investigated by mechanical testing on a total of 78 single- and multi-bay prototype structures, which are full scale equivalent to subs-structures of an $80 \mathrm{~m}$ long aluminum high speed vessel structure. Welding induced initial imperfections significantly affect the ULS behavior, and it is thus of vital importance to identify the features of initial imperfections prior to the ULS computations and design. In this regard, the statistics of welding induced initial imperfections on the prototype structures are measured and analyzed. The buckling collapse testing is undertaken until and after the ULS is reached. Nonlinear FEA solutions are also obtained for the prototype structures. Based on the experimental and numerical results, closed-form ULS formulae are developed.

In the past, useful studies on mechanical collapse testing of welded aluminum structures have of course been undertaken. In the early 1980s, a series of 76 aluminum un-stiffened plate collapse tests were carried out by Mofflin (1983) and Mofflin \& Dwight (1984) at the University of Cambridge, UK; and these are regarded as perhaps one of the largest and most relevant test programs for the collapse strength of aluminum plating (un-stiffened plates) until now. After TIG (tungsten inert gas) welding in the longitudinal direction and MIG (metal inert gas) welding in the transverse direction, weld induced initial distortions and residual stresses were measured and their influences on the plate collapse behavior were studied on two of the most 
common aluminum alloys used for the construction of high speed vessels, i.e., 5083 and 6082 alloys.

In the late 1980s, Clarke \& Swan (1985) and Clarke (1987) at the Admiralty Research Establishment (ARE), UK carried out the buckling collapse testing on a total of five aluminum stiffened plate structures. This was one of the earliest collapse test programs to use shipshaped aluminum stiffened plate structures using fullscale prototype models of all-welded construction with multiple frame bays. All material of the test structures was equivalent to 5083 aluminum alloy.

Over a decade after the ARE tests, several collapse test programs on aluminum stiffened plate structures constructed by welding were carried out together with various surveys of weld induced initial imperfections. These include Hopperstad et al. (1998, 1999), Tanaka \& Matsuoka (1997), Matsuoka et al. (1999), Zha et al. (2000), Zha \& Moan (2001, 2003) and Aalberg et al. (2001). The material of most test structures was 5083 aluminum alloy for plating and 6082 aluminum alloy for stiffeners.

Except perhaps for those by Tanaka \& Matsuoka (1997) and Matsuoka et al. (1999) which were full-scale prototype models with multiple frame bays, most of these test structures were small scale models composed of a single stiffener with attached plating or a thinwalled cruciform structure. Although the nature and extent of test structures were somewhat limited, these test results were still very useful in studying the statistics of weld induced initial imperfections as well as the compressive collapse strength characteristics themselves.

Even in light of the existing excellent research results on the weld induced initial imperfections and ultimate strength of aluminum structures noted above, more studies are certainly required, because a systematic survey of the initial imperfection and buckling collapse characteristics is very lacking for a variety of aluminum alloy types and structural dimensions typical of shipshaped full-scale prototype structures considering the recent trends in the application of aluminum marine structures.

A significant motive for initiating the present research project was to contribute to resolving the issue noted above to a good degree, by developing relevant design database on fabrication related initial imperfections and ultimate strength of welded aluminum stiffened plate structures for marine applications.

\section{Design and fabrication of test structures}

Table 1 indicates the overall dimensions of prototype structures. A total of 78 prototype aluminum structures that are full-scale equivalent to sub-structures of an $80 \mathrm{~m}$ long all aluminum high-speed vessel are considered. They are designed in terms of single and multi-bay stiffened plate structures as those shown in Fig.1.

While various methods for fabricating aluminum ship structures are today relevant, the present test program adopts the MIG welding technique, which is now one of the most popular methods of welding in aluminum ship construction.

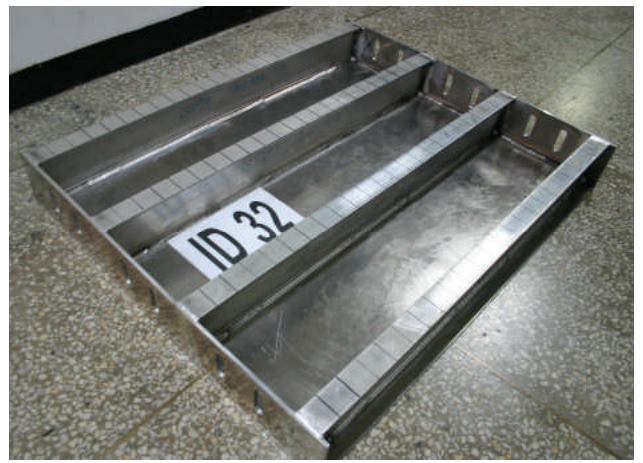

Fig.1(a): One-bay prototype structure

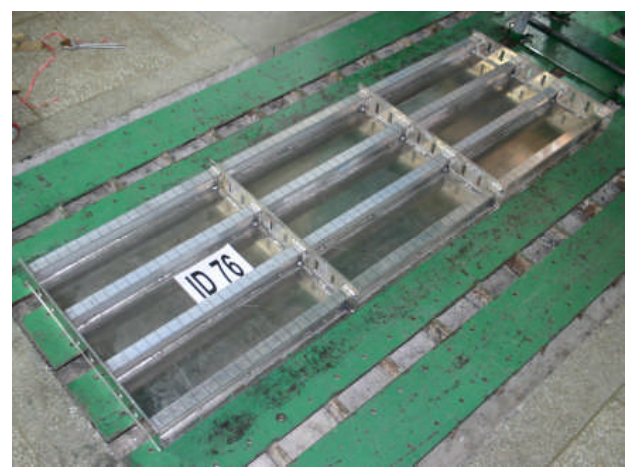

Fig.1(b): Three-bay prototype structure

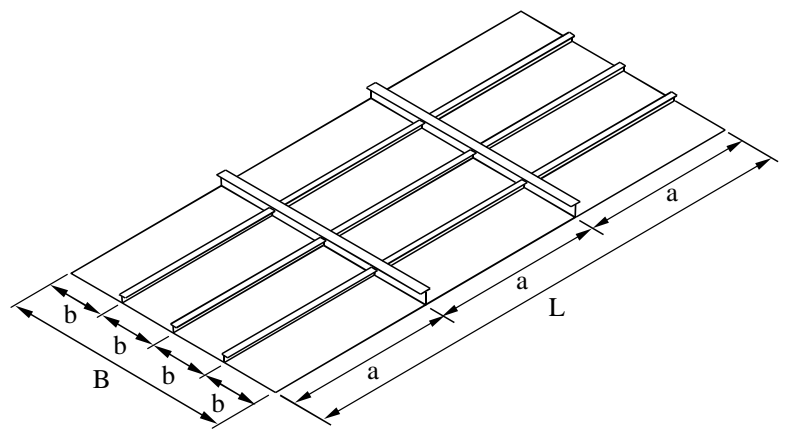

Fig.2: Nomenclature: A stiffened plate structure

To cover the possible diverse range of in-service aluminum marine structures representative of various collapse failure modes, a variety of structural dimensions, material types, plate thicknesses, stiffener types and stiffener web heights are considered as follows (see Fig.2 for the nomenclature):

- Panel width: $\mathrm{B}=1000 \mathrm{~mm}$;

- Stiffener spacing: b = $300 \mathrm{~mm}$;

- Panel length: $1000 \mathrm{~mm}$ (one-bay structure), $1200 \mathrm{~mm}$ (one-bay structure), $3000 \mathrm{~mm}$ (three-bay structure of 1000 mm length);

- Material types: plate - 5083-H116 (rolled), 5383H116 (rolled), stiffeners - 5083-H116 (rolled), 5383H112 (extruded), 5383-H116 (rolled), 6082-T6 (extruded); 
- Thickness: plate $-5 \mathrm{~mm}, 6 \mathrm{~mm}, 8 \mathrm{~mm}$, stiffeners -4 $\mathrm{mm}, 5 \mathrm{~mm}, 6 \mathrm{~mm}, 8 \mathrm{~mm}$;

- Stiffener types: flat bar, built-up T-bar, extruded Tbar;

- Stiffener web height: $60 \mathrm{~mm}, 70 \mathrm{~mm}, 80 \mathrm{~mm}, 90 \mathrm{~mm}$, $100 \mathrm{~mm}, 120 \mathrm{~mm}, 140 \mathrm{~mm}$.

Table 2 indicates the minimum values of mechanical properties of aluminum alloys used for building the prototype structures.

\section{Statistics of weld induced initial imperfections}

When aluminum alloys are locally heated, the heated part will expand but because of adjacent cold part it will be subjected to compressive stress and distortion. When the heated part is cooled down, it will tend to locally shrink and thus now be subjected to a tensile stress. While the same happens in steel structures as well, it is the case that in aluminum structures the aluminum material in the HAZ is typically softened and subsequently the strength (yield stress) of the HAZ is generally reduced, which is termed a material softening phenomenon.

Figure 3 represents a profile of the weld induced initial distortions in a stiffened plate structure, where stiffeners distort in the direction of web and also sideways and plating deflects in the lateral direction. Due to welding, tensile residual stresses remain in the HAZ, and compressive residual stresses develop in the other areas to be in equilibrium of internal forces as shown in Fig.4. The distribution of residual stresses in plating which is welded along multiple stiffener lines or edges may differ from that in stiffener web itself as shown in Fig.5.

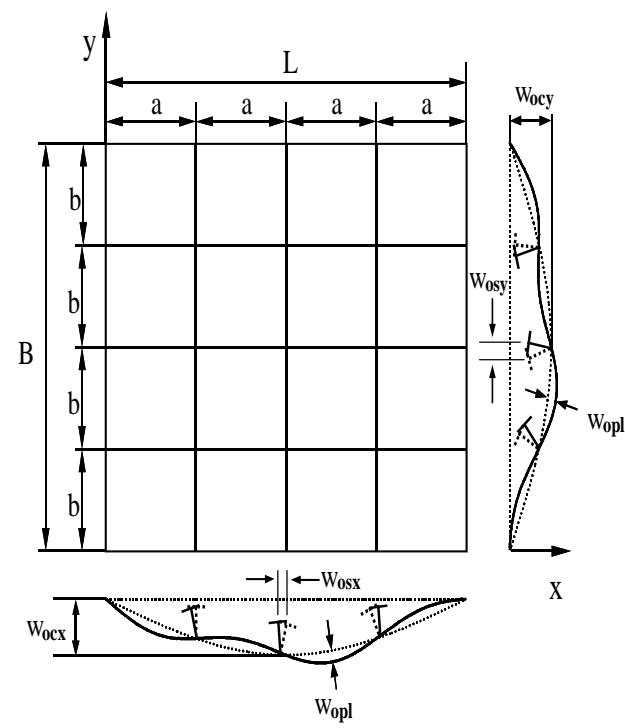

Fig.3: A profile of weld induced initial distortions in a stiffened plate structure

Figure 6 shows idealized schematics of softened regions in the HAZ. In the plating, since stiffeners are assumed to be welded in this case along all four edges, the softening zones develop along all edges as indicated. Its counterpart in the stiffener attached by welding is also shown. In terms of structural behavior in association with softening in the HAZ, the breadth of the softening zones together with the reduction of yield strength plays a primary role in strength characterization.

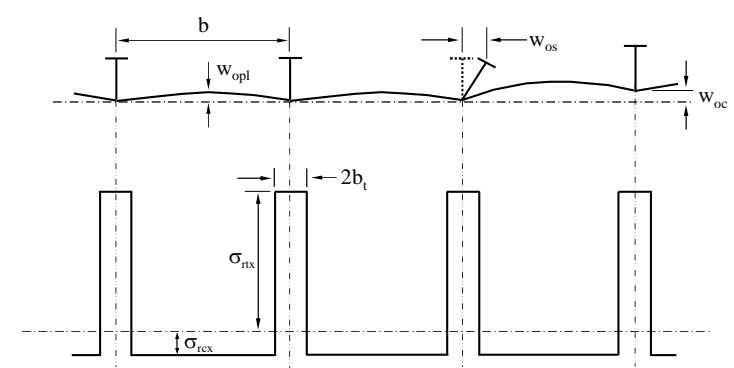

Fig.4: Weld induced initial distortions and residual stresses in a stiffened plate structure
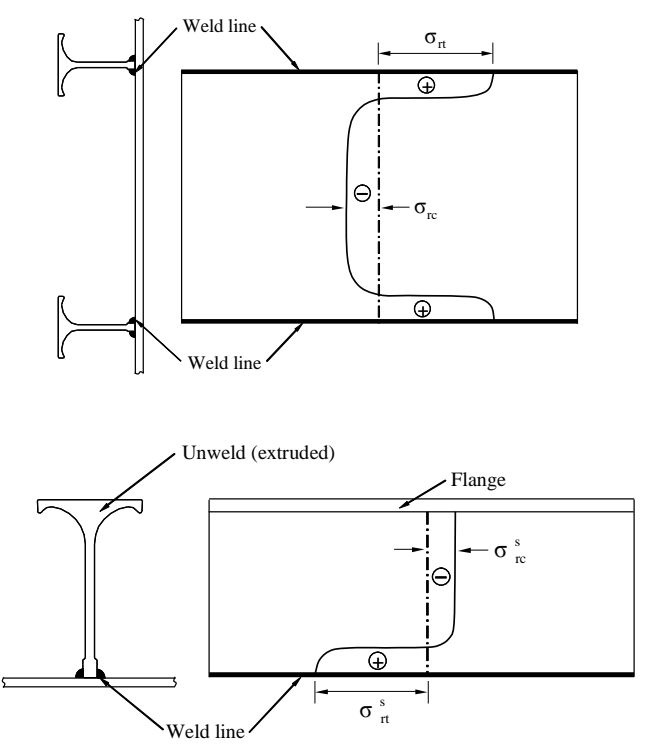

Fig.5: Schematics of the distribution of weld induced residual stresses in a plate welded at two edges, and in the stiffener web welded at one edge (left: plating, right: extruded stiffener web; +: tension, -: compression)
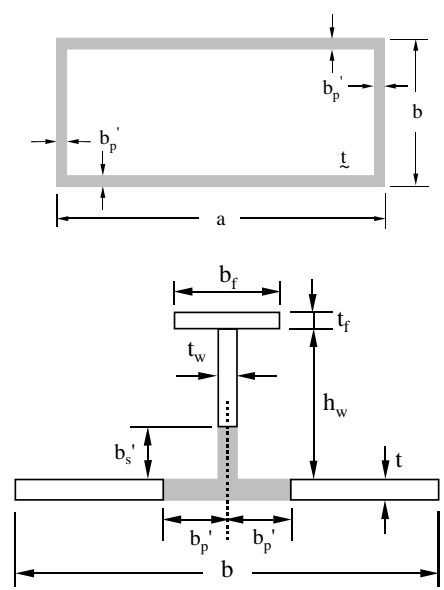

Fig.6: Idealized profiles of softening zones inside an aluminum plate welded at four edges, and its counterpart in the stiffener attachment to plating 
While weld induced initial imperfections described above should be minimized by application of proper welding procedures and fabrication methods, it is nevertheless important to realize that their levels in specific cases can have a remarkable influence on the strength and stiffness of the structures. Hence their levels must be dealt with as parameters of influence in the analysis of load-carrying capacity. This means that such initial imperfection parameters must be properly determined in advance and accounted for in the design process including reliability analyses and code calibrations.

For aluminum stiffened plate structures constructed by welding, the following six types of initial imperfections will generally be pertinent, namely

- Initial distortion of plating between stiffeners;

- Column type initial distortion of stiffener;

- Sideways initial distortion of stiffener;

- Residual stresses of plating between stiffeners;

- Residual stresses of stiffener web;

- Softening in the HAZ in terms of reduction of the HAZ material yield stress and breadth of softened zone.

In the present study, the six types of initial imperfections noted above were measured for all the prototype structures (Paik et al. 2006, Paik 2007a). Figure 7 shows 3-dimensional configurations of selected test structures after welding, indicating initial distortions in terms of plate initial deflection, column type initial deflection of stiffeners, and sideways initial deflections of stiffeners. Figure 8 shows measurements of welding induced residual stresses in plating and stiffener web.

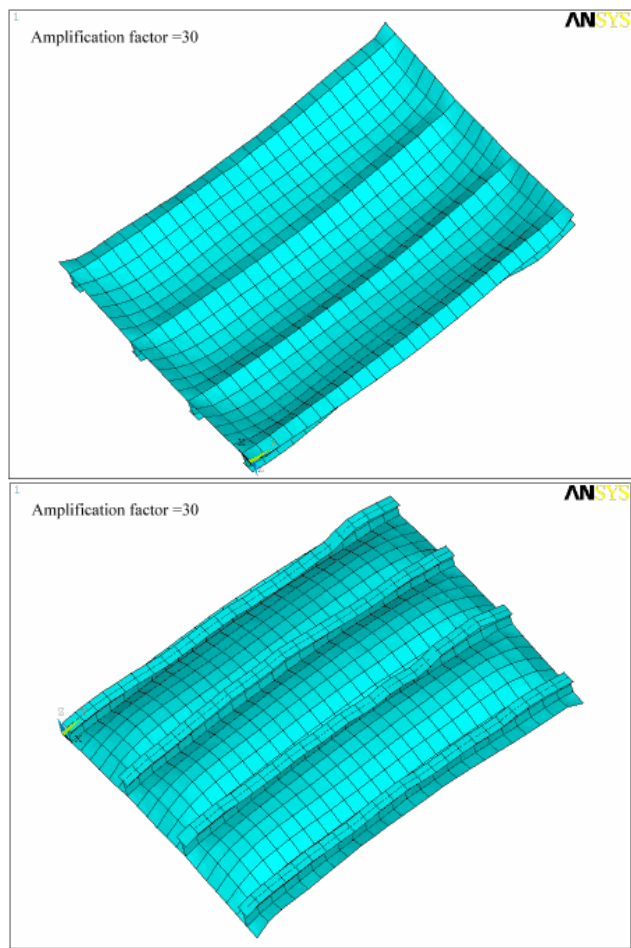

Fig.7(a): 3-dimensional displays of a selected prototype structure distorted after welding, for ID7 with amplification factor of 30

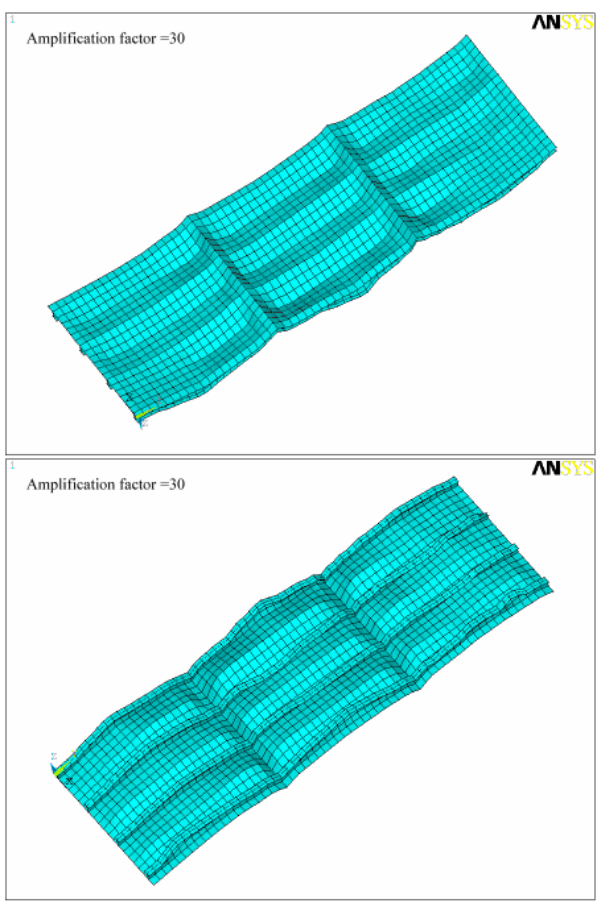

Fig.7(b): 3-dimensional displays of a selected prototype structure distorted after welding, for ID77 with amplification factor of 30

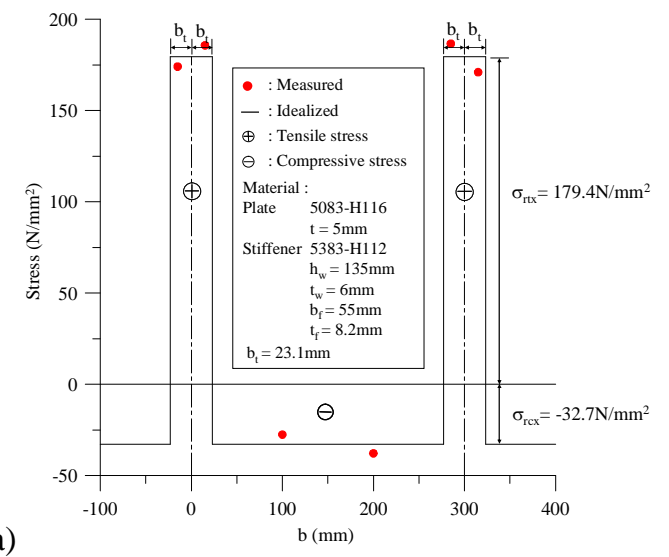

(a)

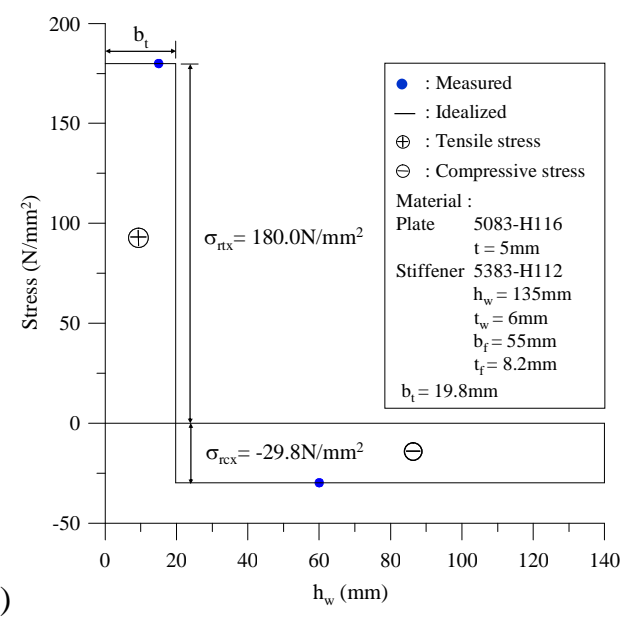

Fig.8: Residual stress distributions at (a) plating, (b) stiffener web for ID4 (5083-H116)

Based on the statistical analyses of the extensive initial imperfection measurements undertaken in the 
present study, the levels of initial imperfection parameters useful for design as well as reliability analyses and code calibrations can be suggested when $5 \%$ and below band data is applied for the slight level analysis and $95 \%$ and above band data is applied for the severe level analysis, as follows

Maximum initial distortion of plating:

$$
\mathrm{w}_{\text {opl }}= \begin{cases}0.018 \beta^{2} \mathrm{t} & \text { for slight level } \\ 0.096 \beta^{2} \mathrm{t} & \text { for average level } \\ 0.252 \beta^{2} \mathrm{t} & \text { for severe level }\end{cases}
$$

where $\beta=\frac{b}{t} \sqrt{\frac{\sigma_{Y}}{E}}=$ plate slenderness ratio.

One half-wave initial distortion amplitude of plating:

$$
\mathrm{w}_{\mathrm{o} 1}= \begin{cases}0.0059 \beta^{2} \mathrm{t} & \text { for slight level } \\ 0.093 \beta^{2} \mathrm{t} & \text { for average level } \\ 0.252 \beta^{2} \mathrm{t} & \text { for severe level }\end{cases}
$$

Localized initial distortion of plating:

$$
\mathrm{w}_{\mathrm{ob}}= \begin{cases}0.00033 \beta^{2} \mathrm{t} \approx 0.0 \text { for slight level } \\ 0.0101 \beta^{2} \mathrm{t} & \text { for average level } \\ 0.0365 \beta^{2} \mathrm{t} & \text { for severe level }\end{cases}
$$

Buckling mode initial distortion of plating:

$$
\mathrm{w}_{\mathrm{om}}= \begin{cases}0.0 & \text { for slight level } \\ 0.00552 \beta^{2} \mathrm{t} & \text { for average level } \\ 0.0468 \beta^{2} \mathrm{t} & \text { for severe level }\end{cases}
$$

Maximum column type initial distortion of stiffener:

$$
\mathrm{w}_{\mathrm{oc}}= \begin{cases}0.00016 \mathrm{a} & \text { for slight level } \\ 0.0018 \mathrm{a} & \text { for average level } \\ 0.0056 \mathrm{a} & \text { for severe level }\end{cases}
$$

One half-wave column type initial distortion of stiffener:

$$
\mathrm{w}_{\mathrm{o} 1}^{\mathrm{c}}= \begin{cases}0.0 & \text { for slight level } \\ 0.00155 \mathrm{a} & \text { for average level } \\ 0.00525 \mathrm{a} & \text { for severe level }\end{cases}
$$

Maximum sideways initial distortion of stiffener:

$$
\mathrm{w}_{\mathrm{os}}= \begin{cases}0.00019 \mathrm{a} & \text { for slight level } \\ 0.001 \mathrm{a} & \text { for average level } \\ 0.0024 \mathrm{a} & \text { for severe level }\end{cases}
$$

One half-wave sideways initial distortion of stiffener:

$$
\mathrm{w}_{\mathrm{o} 1}^{\mathrm{s}}= \begin{cases}0.0 & \text { for slight level } \\ 0.000574 \mathrm{a} & \text { for average level } \\ 0.0018 \mathrm{a} & \text { for severe level }\end{cases}
$$

Yield stress of the HAZ material for 5083-H116:

$$
\frac{\sigma_{\mathrm{YHAZ}}}{\sigma_{\mathrm{Y}}}=\left\{\begin{array}{l}
0.906 \text { for slight level } \\
0.777 \text { for average level } \\
0.437 \text { for severe level }
\end{array}\right.
$$

where $\sigma_{Y}=215 \mathrm{~N} / \mathrm{mm}^{2}$.

Yield stress of the HAZ material for 5383-H116:

$$
\frac{\sigma_{\text {YHAZ }}}{\sigma_{Y}}=\left\{\begin{array}{l}
0.820 \text { for slight level } \\
0.774 \text { for average level } \\
0.640 \text { for severe level }
\end{array}\right.
$$

where $\sigma_{Y}=220 \mathrm{~N} / \mathrm{mm}^{2}$.

Yield stress of the HAZ material for 5383-H112:

$$
\frac{\sigma_{\mathrm{YHAZ}}}{\sigma_{\mathrm{Y}}}=0.891 \text { for average level }
$$

where $\sigma_{Y}=190 \mathrm{~N} / \mathrm{mm}^{2}$.

Yield stress of the HAZ material for 6082-T6:

$$
\frac{\sigma_{Y H A Z}}{\sigma_{Y}}=0.703 \text { for average level }
$$

where $\sigma_{Y}=240 \mathrm{~N} / \mathrm{mm}^{2}$.

Compressive residual stress at plating:

$$
\sigma_{\mathrm{rcx}}=\left\{\begin{array}{l}
-0.110 \sigma_{\mathrm{Yp}} \text { for slight level } \\
-0.161 \sigma_{\mathrm{Yp}} \text { for average level } \\
-0.216 \sigma_{\mathrm{Yp}} \text { for severe level }
\end{array}\right.
$$

Compressive residual stress at stiffener web:

$$
\sigma_{\mathrm{rcx}}=\left\{\begin{array}{l}
-0.078 \sigma_{\mathrm{Ys}} \text { for slight level } \\
-0.137 \sigma_{\mathrm{Ys}} \text { for average level } \\
-0.195 \sigma_{\mathrm{Ys}} \text { for severe level }
\end{array}\right.
$$

Width of the HAZ:

$$
b_{p}^{\prime}=b_{s}^{\prime}=\left\{\begin{array}{l}
11.3 \mathrm{~mm} \text { for slight level } \\
23.1 \mathrm{~mm} \text { for average level } \\
29.9 \mathrm{~mm} \text { for severe level }
\end{array}\right.
$$

\section{Collapse testing}

Figure 9 shows the set-up of the physical collapse testing on the stiffened plate structures. The loaded edges are simply supported and the axial compressive loading is applied at the neutral axis of the panel cross section. A rigid circular bar at each side of loaded edges was inserted as shown in Fig.10 to reflect simply supported edge conditions along the loaded edges, i.e., by minimizing the rotational restraints.

Two types of unloaded edge condition are considered, namely free and simply support conditions, as shown in Figs.9(a) and 9(b) or 9(c), respectively. For the latter condition shown in Fig.9(b) or 9(c), a set of supporting jigs was attached to keep the unloaded edges straight. This condition was considered to reflect the behavior of stiffened panels in a continuous stiffened plate structure.

A total of 10 test structures with flat bar type stiffeners, namely ID40, 41, 42, 44, 45, 58, 59, 60, 62 and 63 were tested without the supporting jigs at unloaded edges, indicating a free edge condition. Figure 11 shows axial compressive loads versus shortening 
curves of selected test structures. It is seen from Fig.11 that the structures exhibit nonlinear behavior until and after the ultimate strength is reached. This is partly due to initial imperfections.

(a)
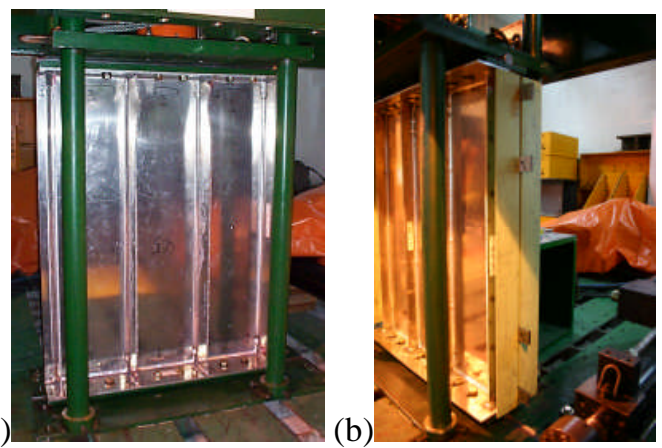

(c)

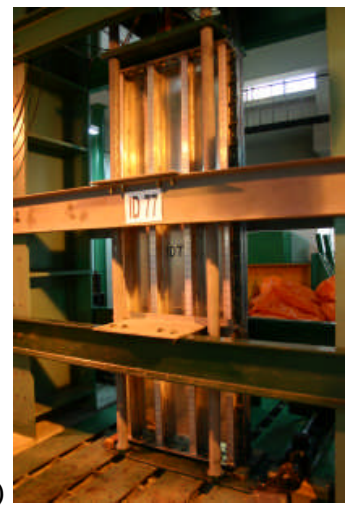

Fig.9: Test set-up for collapse testing on stiffened plate structures, (a) without supporting jigs at unloaded edges, (b), (c) with supporting jigs at unloaded edges to keep straight

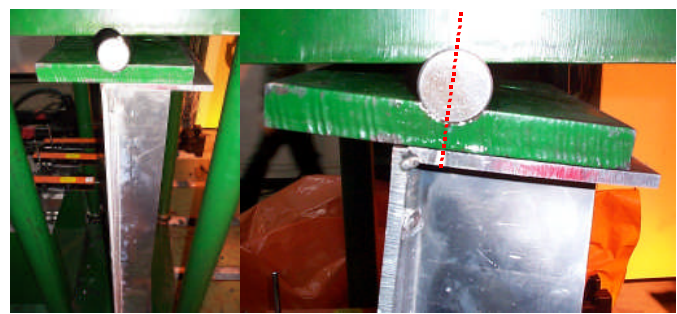

Fig.10: Simply supported condition at loaded edges and axial compressive loading at the neutral axis of the panel cross section

\section{Nonlinear finite element analysis}

Nonlinear finite element analysis (FEA) using ANSYS (2006) was carried out on the test structures by a comparison with FEA and test results. Since some arguments in terms of selecting relevant FEA modeling techniques still remain, 8 types of FEA modeling are in the present study considered with varying the extent of analysis and the direction of column type initial deflection of stiffeners (with the abbreviations of CIP = compression in plate side, CIS = compression in stiffener side, SPM = stiffened panel model, $\mathrm{PSC}=$ plate-stiffener combination model), namely
- 1 bay SPM with initial deflection in CIP

- 1 bay SPM with initial deflection in CIS

- 2 bay SPM with initial deflection in CIP

- 2 bay SPM with initial deflection in CIS

- 1 bay PSC with initial deflection in CIP

- 1 bay PSC with initial deflection in CIS

- 2 bay PSC with initial deflection in CIP

- 2 bay PSC with initial deflection in CIS

\begin{tabular}{|c|c|c|c|c|c|c|c|}
\hline \multirow{2}{*}{ ID 1} & \multicolumn{2}{|c|}{ Plate } & \multicolumn{5}{|c|}{ Stiffener } \\
\hline & t & \begin{tabular}{|l|} 
Material \\
\end{tabular} & $h_{w}$ & $t_{w}$ & $b_{f}$ & $t_{f}$ & Material \\
\hline & $5 \mathrm{~mm}$ & 5083-H116 & $55.7 \mathrm{~mm}$ & $3.7 \mathrm{~mm}$ & $40 \mathrm{~mm}$ & $6.7 \mathrm{~mm}$ & 5383-H112 \\
\hline
\end{tabular}

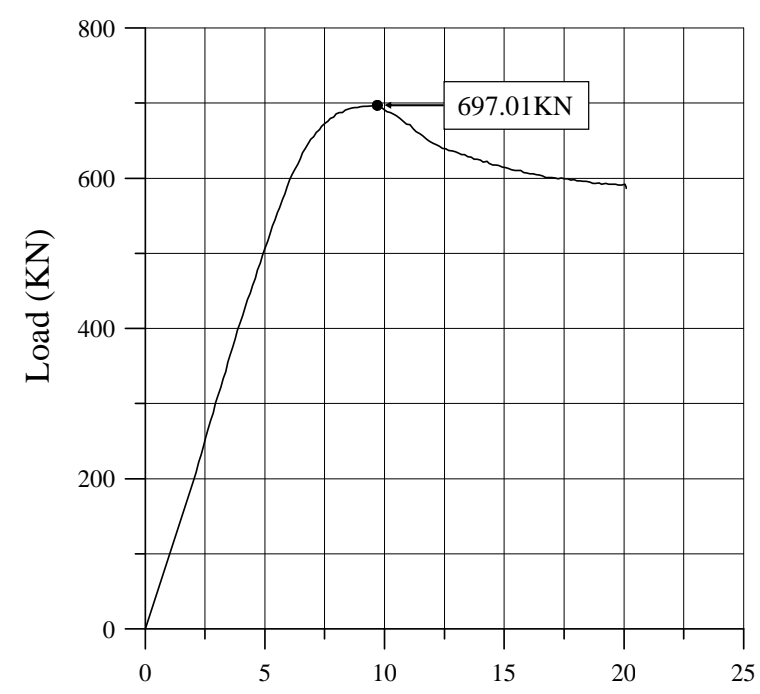

(a)

Displacement (mm)
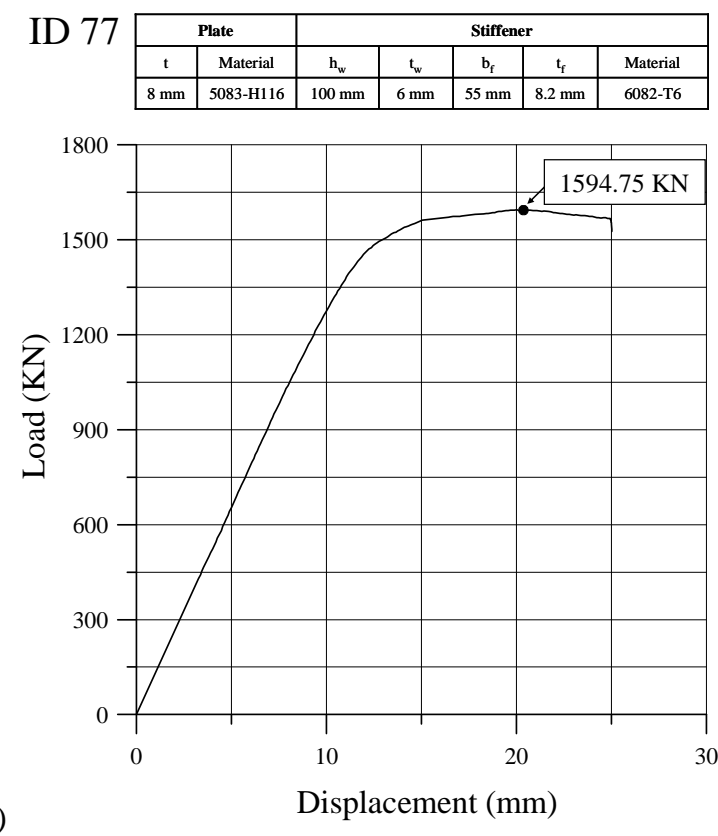

Fig.11: Axial compressive loads versus shortening curves for (a) ID1 and ID77, obtained by the experiment

In addition to the 8 types of modeling noted above, another 2 bay FE model was considered by reflecting the unloaded edges as being simply supported keeping them straight, namely

- 2 bay SPM with all (four) edges simply supported 
While the test structures are primarily 1 bay system, i.e., considering the longitudinally stiffened panels between two transverse frames, 2 bay system including transverse frames as shown in Fig.12 are also considered in the present FEA to reflect the continuity support condition along the transverse frames in a continuous plate structure.

All of the 1 bay models are analyzed by a load control, while the 2 bay models are loaded by a displacement control, because of easier handling for the load application with regard to the neutral axis at the panel cross section.

After some convergence studies, the FE mesh size adopted has one plate-shell element representing the HAZ at plating and at the stiffener web. Ten plate-shell elements represent the plating between stiffeners and six elements model stiffener web, including the elements in the HAZ.
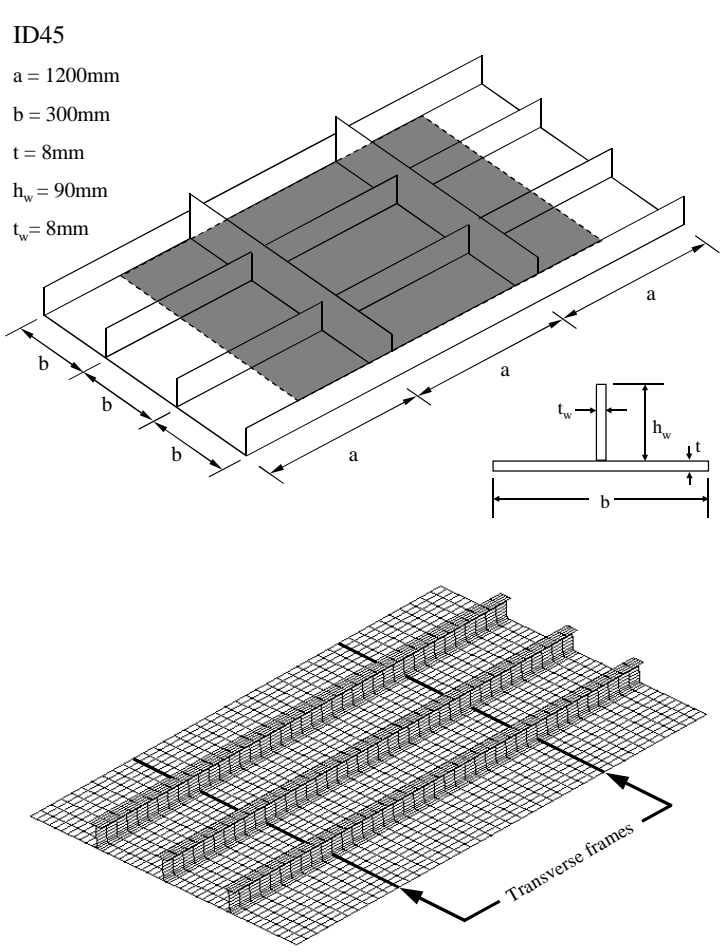

Fig.12(a): The extent and structural modeling for the 2 bay stiffened panel model (SPM) FEA

Figure 13 compares FEA solutions obtained by the 9 types of FE modeling noted above together with test data for two selected test panels until and after the ULS is reached. It is to be noted in Fig. 13 that all FEA except for No. 10 were undertaken considering that the unloaded edges are free as in the actual testing, while No.10 was considered that the unloaded edges (as well as the loaded edges) are simply supported keeping them straight.

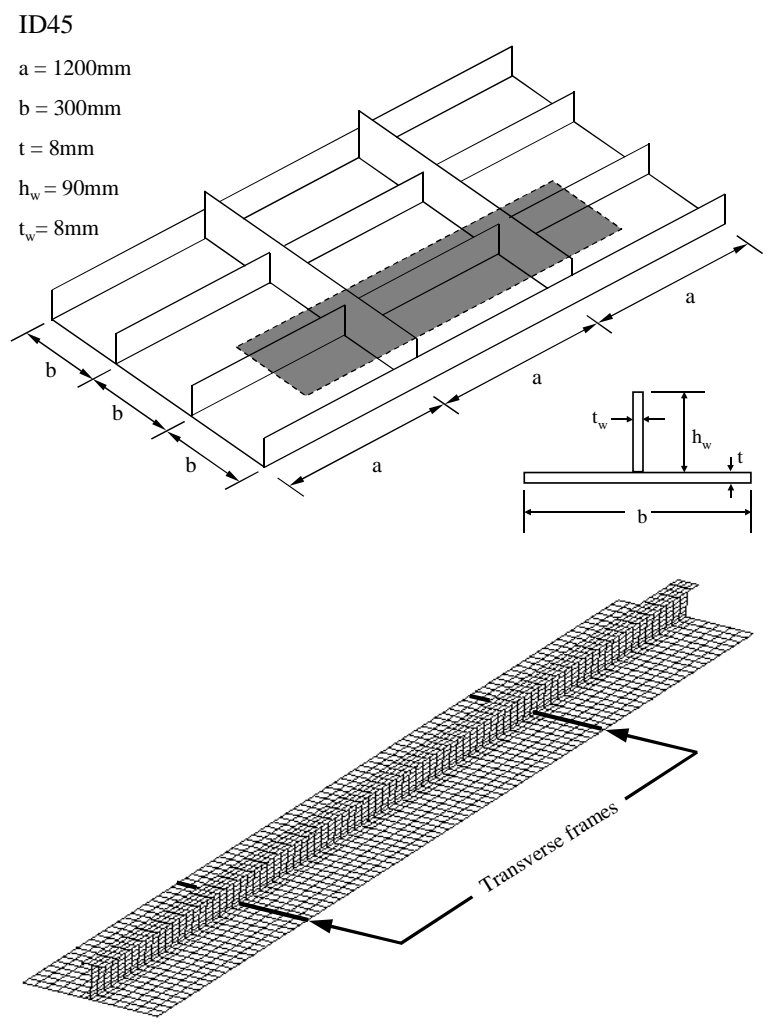

Fig.12(b): The extent and structural modeling for the 2 bay plate-stiffener combination (PSC) FEA

In the actual test, the panel ID 40 collapsed by column type collapse (Mode III) and ID 63 collapsed by stiffener tripping (Mode V). As would be expected, it is evident that the direction of column type initial deflection of stiffener significantly affects the FE solutions.

It is also seen that the 2 bay FEA always gives a larger ULS than 1 bay FEA. This is because the 2 bay FEA involves the rotational restraint effects along the transverse frames in the continuous plate structures.

It is to be noted that the different FE modeling approaches give quite different solutions. It is of vital importance to correctly reflect all of the influential parameters in the FE modeling in this regard. It is important to realize that the direction of column type initial deflections of stiffeners, among other factors may significantly affect the ultimate strength behavior when the magnitude of initial deflections is substantially large.

Also, it is evident that the model type or extent taken for the FE analysis must be determined carefully, while the real material stress-strain relationship rather than the elastic-perfectly plastic material approximation must always be employed unlike the ULS assessment of steel structures. Since softening in the HAZ plays a significant role on the welded aluminum plate structures, it must be carefully dealt with as well. 


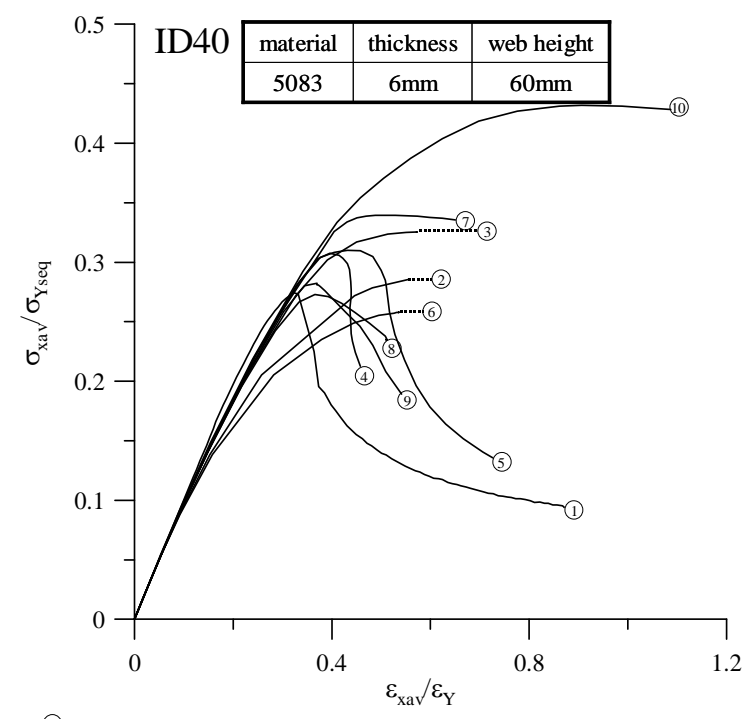

(1) Experiment, collapse mode III (CIP)

(2) 1 bay FEA(SPM), collapse mode III (CIP), column type initial def lection with CIP (3) 1 bay FEA(SPM), collapse mode III (CIP), column type initial def lection with CIS (4) 2 bay FEA(SPM), collapse mode III (CIP), column type initial def lection with CIP (5) 2 bay FEA(SPM), collapse mode $\mathrm{V}$ (CIS), column type initial defle ction with CIS (6) 1 bay FEA(PSC), collapse mode III (CIP), column type initial def lection with CIP (7) 1 bay FEA(PSC), collapse mode III (CIP), column type initial def lection with CIS (8) 2 bay FEA(PSC), collapse mode III (CIP), column type initial def lection with CIP (9) 2 bay FEA(PSC), collapse mode $\mathrm{V}$ (CIS), column type initial defle ction with CIS

(1D) 2 bay FEA(SPM), collapse mode III (CIP), column type initial def lection with CIP (All edges simply supported keeping them straight )

Note: $\mathrm{CIP}=$ compression in plate side, $\mathrm{CIS}=$ compression in stif fener side

\section{(a) 5083 panel}

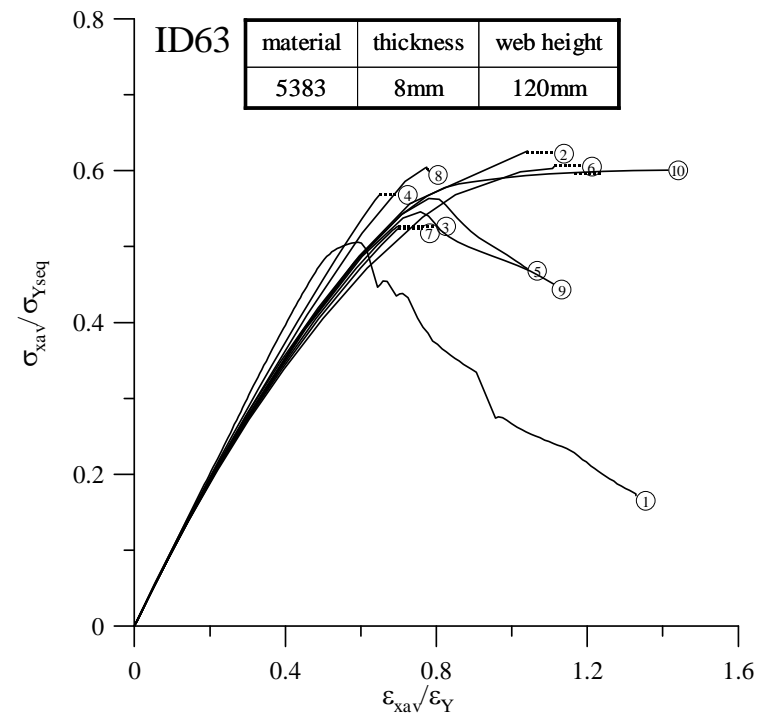

(1) Experiment, collapse mode V (CIS)

(2) 1 bay FEA(SPM), collapse mode III (CIP), column type initial def lection with CIP (3) 1 bay FEA(SPM), collapse mode V (CIS), column type initial defle ction with CIS (4) 2 bay FEA(SPM), collapse mode III (CIP), column type initial def lection with CIP (5) 2 bay FEA(SPM), collapse mode V (CIS), column type initial defle ction with CIS (6) 1 bay FEA(PSC), collapse mode III (CIP), column type initial def lection with CIP (7) 1 bay FEA(PSC), collapse mode V (CIS), column type initial defle ction with CIS (8) 2 bay FEA(PSC), collapse mode III (CIP), column type initial def lection with CIP (9) 2 bay FEA(PSC), collapse mode V (CIS), column type initial defle ction with CIS (10) 2 bay FEA(SPM), collapse mode $\mathrm{V}$ (CIS), column type initial defle ction with CIS (All edges simply supported keeping them straight)

Note: $\mathrm{CIP}=$ compression in plate side, $\mathrm{CIS}=$ compression in stif fener side

\section{(b) 5383 panel}

Fig.13: Comparison of FEA solutions as those obtained by 9 types of FE modeling together with test data for (a) a 5083 panel, (b) a 5383 panel
These aspects definitely make the aluminum panel ULS evaluation works cumbersome. In this regard, the present study adopts the following four types of FEA models for the test structures, namely

- 1 bay PSC model in CIP

- 1 bay PSC model in CIS

- 2 bay PSC model in CIP

- 2 bay PSC model in CIS

It is assumed that the material follows the elasticperfectly plastic behavior neglecting strain-hardening effect. An 'average level' of initial imperfections including initial distortions, welding residual stresses and HAZ softening as measured for the test structures is applied for the FEA.

The mechanical properties (e.g., elastic modulus, yield stress) of aluminum alloys used for the present FEA were defined from the minimum values of classification society rules rather than actual values obtained from the tensile coupon tests.

\section{Summary of experimental and numerical results}

Table 3 summarizes the ultimate strengths of test structures together with collapse modes obtained by the experiment and nonlinear FEA. Theoretically, six primary modes of stiffened panel collapse under predominantly axial compressive loads are considered, namely (Paik \& Thayamballi 2003)

- Mode I: Overall collapse of plating and stiffeners as a unit;

- Mode II: Collapse under predominantly biaxial compression;

- Mode III: Beam-column type collapse;

- Mode IV: Local buckling of stiffener web;

- Mode V: Tripping of stiffener;

- Mode VI: Gross yielding.

It was observed that the panel collapse patterns were clearly different depending on the panel geometries. For the ratio of stiffener web height to web thickness is relatively large, the stiffened panel mostly collapsed by lateral torsional buckling or tripping (Mode V), while the beam-column type collapse (Mode III) took place for panels with a smaller web height. For some panels with high T-bars, local web buckling (Mode IV) tends to occur.

Also, from the numerical computations, it is observed that the 2-bay FEA models give greater ultimate strength values than the 1-bay FEA models because the effect of rotational restraints along the transverse frames is taken into account in the 2-bay FEA models. 


\section{Closed-form ULS formulae}

In ship design, the hull girder strength of ships is often governed by the buckling collapse behavior of deck or bottom panels. Hence the calculation of the buckling collapse strength of stiffened panels in deck and bottom structures under axial compressive loads, which are a primary load component due to ship's hull girder actions, is an essential task.

Closed-form empirical ULS formulae for aluminum stiffened plate structures under axial compressive loads are derived by the regression analysis of experimental and numerical database obtained from the present study (Paik 2007b).

To cover a wider range of plate slenderness ratio and column slenderness ratio in the developed ULS formulae, some additional FEA were undertaken for stiffened plate structures with different plate slenderness ratio and column slenderness ratio from those of prototype structures tested in the present study.

When the continuous stiffened plate structure is modeled as an assembly of plate-stiffener combinations, it is recognized that the ultimate compressive strength of the representative plate-stiffener combination is expressible as follows (Paik \& Thayamballi 1997, 2003)

$$
\frac{\sigma_{\mathrm{u}}}{\sigma_{\mathrm{Yeq}}}=\left[\mathrm{C}_{1}+\mathrm{C}_{2} \lambda^{2}+\mathrm{C}_{3} \beta^{2}+\mathrm{C}_{4} \lambda^{2} \beta^{2}+\mathrm{C}_{5} \lambda^{4}\right]^{-0.5} \leq \frac{1}{\lambda^{2}}
$$

where $\mathrm{C}_{1} \sim \mathrm{C}_{5}=$ coefficients to be determined from database.

For steel stiffened plate structures with an average level of weld induced initial imperfections, Paik and Thayamballi $(1997,2003)$ determined the coefficients of Eq.(16) by the least square method based on the experimental database as follows

$$
\frac{\sigma_{\mathrm{u}}}{\sigma_{\text {Yeq }}}=\left[0.995+0.936 \lambda^{2}+0.170 \beta^{2}+0.188 \lambda^{2} \beta^{2}-0.067 \lambda^{4}\right]^{-0.5} \leq \frac{1}{\lambda^{2}}
$$

It is to be noted that $\sigma_{\mathrm{Yeq}} / \lambda^{2}$ is the elastic buckling stress of a column member simply supported at both ends, and the ultimate strength of a column member should not be greater than the elastic buckling stress. Eq.(17) is useful for predicting the ultimate compressive strength of steel stiffened panels with Tee, angle or flat bars, the last type of stiffeners having relatively large column slenderness ratio, when an average level of initial imperfections is applied.

For aluminum stiffened plate structures, the use of a similar approach to steel stiffened plate structures was attempted but with different formulae for different types of stiffeners. We then suggest the following constants for aluminum stiffened plate structures with extruded or built-up T-bars when an average level of weld induced initial imperfections are applied, namely

$$
\frac{\sigma_{\mathrm{u}}}{\sigma_{\mathrm{Yeq}}}=\left[1.318+2.759 \lambda^{2}+0.185 \beta^{2}-0.177 \lambda^{2} \beta^{2}+1.003 \lambda^{4}\right]^{-0.5} \leq \frac{1}{\lambda^{2}}
$$

Figure 14 checks the accuracy of Eq.(18) together with Eq.(17) for steel stiffened plate structures. The bias and COV of Eq.(18) are 1.032 and 0.101, respectively. On the other hand, the ultimate strength of aluminum stiffened plate structures with flat bars can be given as a smaller value of the following two formula solutions, when an average level of initial imperfections is applied, namely

$$
\frac{\sigma_{\mathrm{u}}}{\sigma_{\mathrm{Yeq}}}=\operatorname{Min} .\left\{\begin{array}{l}
{\left[2.500-0.588 \lambda^{2}+0.084 \beta^{2}+0.069 \lambda^{2} \beta^{2}+1.217 \lambda^{4}\right]^{-0.5} \leq \frac{1}{\lambda^{2}}} \\
{[-16.297+18.776 \lambda+17.716 \beta-22.507 \lambda \beta]^{-0.5}}
\end{array}\right.
$$

Figure 15 checks the accuracy of Eq.(19) by a comparison with experimental and numerical results. Considering the uncertainty associated with initial imperfections and structural modeling techniques, among other factors, it is interesting to see the upper and lower limits of the panel ultimate strength with relevant deviations. Except for very thick panels with Tbars, i.e., with $\beta=2.08$ and 2.10 , all experimental and numerical data of the panel ultimate strength are located in the range of $\pm 20 \%$ deviations.

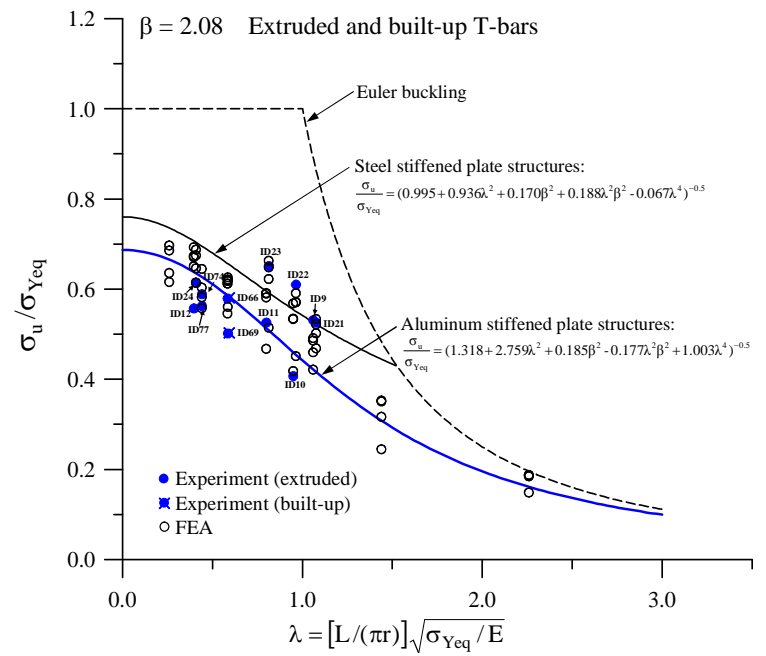

(a) $\beta=2.08$

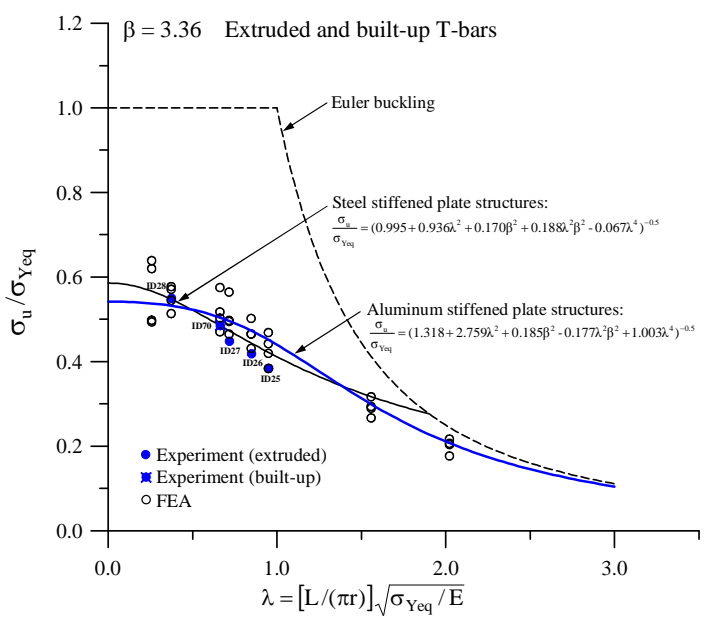

(b) $\beta=3.36$

Fig.14: The accuracy of the closed-form empirical ULS formula, Eq.(18), for aluminum stiffened plate structures with T-bars, (a) $\beta=2.08$, (b) $\beta=3.36$ 


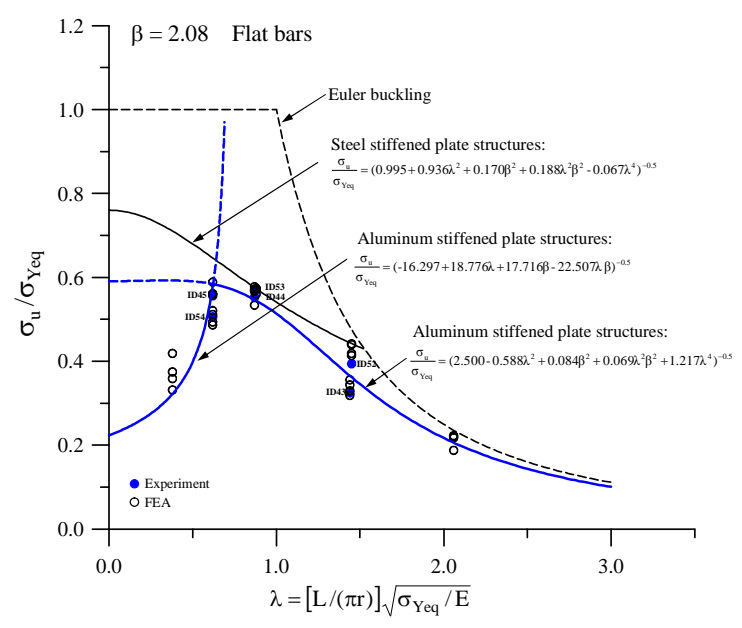

(a) $\beta=2.08$

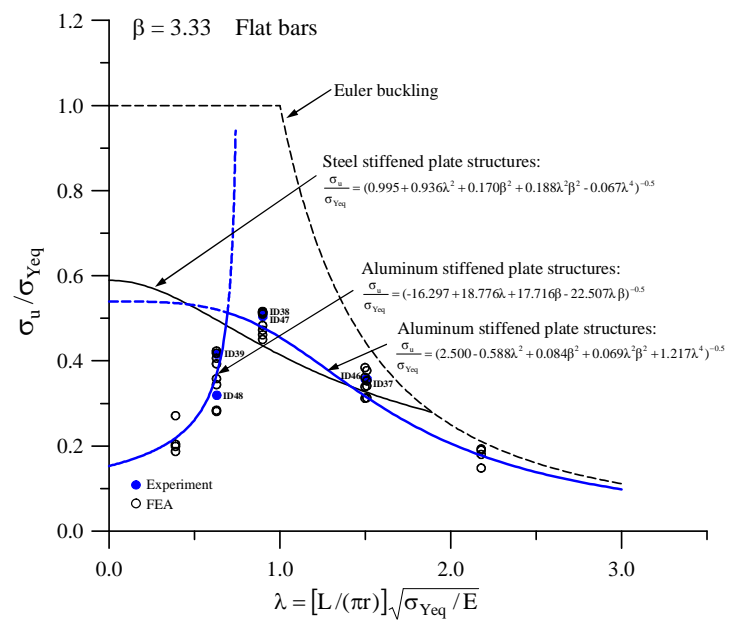

(b) $\beta=3.33$

Fig.15 The accuracy of the closed-form empirical ULS formula, Eq.(19), for aluminum stiffened plate structures with flat bars, (a) $\beta=\mathbf{2 . 0 8}$, (b) $\beta=3.33$

\section{Concluding remarks}

During the last decade, the application of aluminum alloys to marine structures such as high-speed vessels and littoral surface crafts has been rapidly increasing. To operate in increasingly harsher environments, the size of high-speed vessels has also grown. Subsequently, the structural design and building process to ensure the structural safety has become more complex in terms of limit state strength assessment and fabrication quality control among others.

In addition to more conventional structural design standards, the use of ULS design method will make possible to design and build very large aluminum high speed vessel structures that can operate in open ocean.

The aims of the present study have been to develop statistical database of fabrication related initial imperfections, and database of experimental and numerical results on the ultimate strength for aluminum stiffened plate structures, and also to derive closed-form empirical ULS formulae.

A total of 78 full-scale prototype aluminum structures, which are equivalent to sub-structures of an $80 \mathrm{~m}$ long aluminum high speed vessel, were constructed by MIG welding and a total of 6 types of fabrication related initial imperfections, which govern the loadcarrying capacity were measured.

By statistical analyses of initial imperfection measurements, three different levels (i.e., slight, average and severe levels) of each of the six type initial imperfection parameters were determined which can be used as reference levels of initial imperfections in ultimate limit strength assessment in association with reliability analyses and code calibrations for welded aluminum marine structures.

Buckling collapse testing on the prototype structures was undertaken. The load-axial displacement curves were obtained until and after the ultimate strength is reached. Nonlinear elastic-plastic large deflection finite element analyses were performed for the prototype structures. The ultimate strength characteristics of the structures together with collapse modes were investigated in terms of plate slenderness ratio and column slenderness ratio as well as initial imperfections.

Closed-form empirical ULS formulas for aluminum stiffened plate structures were developed by the regression analysis of experimental and numerical ultimate strength database obtained from the present study.

It is believed and hoped that the database and insights developed from the present study will be very useful for ultimate limit state design and strength assessment of aluminum stiffened plate structures which are used for building very large high speed ships such as passenger ships, war ships, littoral surface or combat ships.

\section{Acknowledgements}

The present study was undertaken at the Ship and Offshore Structural Mechanics Laboratory (SSML), Pusan National University, Korea, which is a National Research Laboratory funded by the Korea Science and Engineering Foundation (Grant No. ROA-2006-00010239-0). The authors are pleased to acknowledge the support of Ship Structure Committee, USA, Alcan Marine, France, and Hanjin Heavy Industries \& Construction Company, Korea.

\section{References}

Aalberg, A., Langseth, M. and Larsen, P.K. (2001). Stiffened aluminum panels subjected to axial compression. Thin-Walled Structures, Vol.39, pp.861-885.

Antoniou, A.C. (1980). On the maximum deflection of plating in newly built ships. Journal of Ship Research, Vol.24, No.1, pp.31-39

Antoniou, A.C., Lavidas, M. and Karvounis, G. (1984). On the shape of post-welding deformations of plate panels in newly built ships. Journal of Ship Research, Vol.28, No.1, pp.1-10

Bradfield, C.D. (1974). Analysis of measured distortions in steel box-girder bridges. Cambridge University Engineering Department, Report CUED/C-Struct/TR42. 
Carlsen, C.A. and Czujko, J. (1978). The specification of postwelding distortion tolerances for stiffened plates in compression. The Structural Engineer, Vol.56A, No.5, pp.133-141

Czujko, J. and Kmiecik, M. (1975). Post welding distortions of ship shell plating. Ship Research Institute Report No.4-5, Technical University of Szczecin, Poland.

Czujko, J. (1980). Probabilistic estimation of load carrying capacity of axially compressed plates with random post-welding distortions. The Norwegian Institute of Technology, The University of Trondheim, Norway.

DNV (2003). Rules for ships / high speed, light craft and naval surface craft. Det Norske Veritas, Oslo, Norway

Ellis, L.G. (1977). A statistical appraisal of the measured deformations in several steel box girder bridge. Journal of Strain Analysis, Vol.12, No.2, pp.97-106.

EN 13195-1 (2002). Aluminum and aluminum alloys: wrought and cast products for marine applications (shipbuilding, marine and offshore). European Standard: French Standard, Association Francaise de Normalisation (AFNOR), Pasris.

Faulkner, D. (1975). A review of effective plating for use in the analysis of stiffened plating in bending and compression. Journal of Ship Research, Vol.19, No.1, pp.1-17

Hopperstad, O.S., Langseth, M. and Hanssen, L. (1998). Ultimate compressive strength of plate elements in aluminum: Correlation of finite element analyses and tests. Thin-Walled Structures, Vol. 29, pp.31-46.

Hopperstad, O.S., Langseth, M. and Tryland, T. (1999). Ultimate strength of aluminum alloy outstands in compression: experiments and simplified analyses. Thin-Walled Structures, Vol. 34, pp. 279-294.

Kmiecik, M (1970). The load carrying capacity of axially loaded longitudinally stiffened plates having initial deformation. Ship Research Institute Report No.R80, Technical University of Szczecin, Poland.

Kmiecik, M. (1971). Behavior of axially loaded simply supported long rectangular plates having initial deformations. SFI, Trondheim, Norway.

Kmiecik, M. (1981). Factors affecting the load-carrying capacity of plates. Ship Research Institute Report No.115, Technical University of Szczecin, Poland.

Kmiecik, M. (1986-1987). A review of fabrication distortion tolerances for ship plating in the light of the compressive strength of plates. Paper No.6, Lloyd's Register Technical Association, London.

Kmiecik, M., Jastrzebski, T. and Kuzniar, J. (1995). Statistics of ship plating distortions. Marine Structures, Vol.8, pp.119-132.

Kontoleon, M.J., Preftitsi, F.G. and Baniotopoulos, C.C. (2000). Butt-welded aluminum joints: a numerical study of the HAZ effect on the ultimate tension strength. The paramount role of joints into the reliable response of structures, Edited by C.C. Baniotopoulos and F. Wald, pp. 337-346.

Masubuchi, K. (1980). Analysis of welded structures Residual stresses, distortion and their consequences. Pergamon Press, Oxford.
Matsuoka, K., Tanaka, Y. and Fujita, Y. (1998). Buckling strength of lightened aluminum hull structures. Proceedings of INALCO'98, International Conference on Aluminum Structural Design, Cambridge, UK, April 15-17.

Mazzolani, F.M. (1985). Aluminum alloy structures. Pitman Advanced Publishing Program, Boston.

Mofflin, D.S. (1983). Plate buckling in steel and aluminum. Ph.D. Thesis, University of Cambridge, UK.

Mofflin, D.S. and Dwight, J.B. (1984). Buckling of aluminum plates in compression. In: Behavior of Thin-Walled Structures, Elsevier, pp.399-427.

Paik, J.K., et al. (2006). The statistics of weld induced initial imperfections in aluminum stiffened plate structures for marine application. International Journal of Maritime Engineering, Vol.148, Part A4, pp.1-50.

Paik, J.K. (2007a). Characteristics of welding induced initial deflections in welded aluminum plates. ThinWalled Structures, Vol.45, pp.493-501.

Paik, J.K. (2007b). Empirical formulations for predicting the ultimate compressive strength of welded aluminum stiffened panels. Thin-Walled Structures, Vol.45, pp.171-184.

Paik, J.K. and Thayamballi, A.K. (1997). An empirical formulation for predicting the ultimate compressive strength if stiffened panels. Proceedings of International Offshore and Polar Engineering Conference, Honolulu, Vol.IV, pp.328-338.

Paik, J.K. and Thayamballi, A.K. (2003). Ultimate limit state design of steel-plated structures. John Wiley \& Sons, Chichester, UK.

Paik, J.K. and Thayamballi, A.K. (2007). Ship-shaped offshore installations: Design, building, and operation. Cambridge University Press, Cambridge, UK.

Paik, J.K., Thayamballi, A.K. and Lee, J.M. (2004). Effect of initial deflection shape on the ultimate strength behavior of welded steel plates under biaxial compressive loads. Journal of Ship Research, Vol.48, No.1, pp.45-60.

Paik, J.K. and Duran, A. (2004). Ultimate strength of aluminum plates and stiffened panels for marine applications. Marine Technology, Vol. 41, No 3, pp. 108-121.

Paik, J.K., Hughes, O.F., Hess, P.E. and Renaud, C. (2005). Ultimate limit state design technology for aluminum multi-hull ship structures. SNAME Transactions, Vol. 113, pp.270-305.

Raynaud, G.M. (1995). New aluminum products for high speed light crafts. Building High-speed Aluminum Marine Vessels in Victoria - A Feasibility Study, Business Victoria, Melbourne, Australia.

Smith, C.S. and Dow, R.S. (1984). Effects of localized imperfections on compressive strength of long rectangular plates. Journal of Constructional Steel Research, Vol.4, pp.51-76 
Smith, C.S., Davidson, P.C., Chapman, J.C. and Dowling, P.J. (1988). Strength and stiffness of ships' plating under in-plane compression and tension, RINA Transactions, Vol. 130, pp. 277-296.

Somerville, W.L., Swan, J.W. and Clarke, J.D. (1977). Measurement of residual stresses and distortions in stiffened panels. Journal of Strain Analysis, Vol.12, No.2, pp.107-116.

Timoshenko, S.P. and Gere, J.M. (1961). Theory of elastic stability. McGraw-Hill, New York. Timoshenko, S.P. and Woinowsky-Krieger, S. (1981). Theory of plates and shells. McGraw-Hill, New York.

Tanaka, Y. and Matsuoka, K. (1997). Buckling strength of lightened aluminum hull structures. Proceedings of the $7^{\text {th }}$ International Offshore and Polar Engineering Conference, Vol.4, Honolulu, pp.790797.
Ueda, Y. and Yao, T. (1985). The influence of complex initial deflection modes on the behavior and ultimate strength of rectangular plates in compression. Journal of Constructional Steel Research, Vol.5, pp.265-302

Zha, Y., Moan, T. and Hanken, E. (2000). Experimental and numerical studies of torsional buckling of stiffener in aluminum panels. Proceedings of the $8^{\text {th }}$ International Offshore and Polar Engineering Conference, Seattle, pp.249-255.

Zha, Y. and Moan, T. (2001). Ultimate strength of stiffened aluminum panels with predominantly torsional failure modes. Thin-Walled Structures, Vol.39, No.8, pp.631-648.

Zha, Y. and Moan, T. (2003). Experimental and numerical collapse prediction of flat bar stiffeners in aluminum panels. Journal of Structural Engineering, Vol.129, No.2, pp.160-168.

Table 1: Overall characteristics of the 78 prototype structures

One bay test plate structures $(1200 \mathrm{~mm} \times 1000 \mathrm{~mm})$ with no replications:

\begin{tabular}{|c|c|c|c|c|c|c|c|c|}
\hline \multirow{2}{*}{ ID } & \multicolumn{2}{|r|}{ Plate } & \multicolumn{6}{|c|}{ Stiffener } \\
\hline & $\mathrm{t}(\mathrm{mm})$ & Alloy and temper & Type & $\mathrm{h}_{\mathrm{w}}(\mathrm{mm})$ & $\mathrm{t}_{\mathrm{w}}(\mathrm{mm})$ & $\mathrm{b}_{\mathrm{f}}(\mathrm{mm})$ & $\mathrm{t}_{\mathrm{f}}(\mathrm{mm})$ & Alloy and temper \\
\hline 1 & 5 & $5083-\mathrm{H} 116$ & Extruded Tee & 55.7 & 3.7 & 40 & $(6.7)$ & $5383-\mathrm{H} 112$ \\
\hline 2 & 5 & 5083-H116 & Extruded Tee & 66.1 & 4 & 40 & $(5.7)$ & 5383-H112 \\
\hline 3 & 5 & 5083-H116 & Extruded Tee & 76.8 & 4 & 45 & $(5.6)$ & 5383-H112 \\
\hline 4 & 5 & 5083-H116 & Extruded Tee & 135 & 6 & 55 & $(8.2)$ & 5383-H112 \\
\hline 5 & 6 & 5083-H116 & Extruded Tee & 55.7 & 3.7 & 40 & $(6.7)$ & 5383-H112 \\
\hline 6 & 6 & 5083-H116 & Extruded Tee & 66.1 & 4 & 40 & $(5.7)$ & 5383-H112 \\
\hline 7 & 6 & 5083-H116 & Extruded Tee & 76.8 & 4 & 45 & (5.6) & 5383-H112 \\
\hline 8 & 6 & 5083-H116 & Extruded Tee & 135 & 6 & 55 & $(8.2)$ & 5383-H112 \\
\hline 9 & 8 & 5083-H116 & Extruded Tee & 55.7 & 3.7 & 40 & $(6.7)$ & 5383-H112 \\
\hline 10 & 8 & 5083-H116 & Extruded Tee & 66.1 & 4 & 40 & $(5.7)$ & 5383-H112 \\
\hline 11 & 8 & 5083-H116 & Extruded Tee & 76.8 & 4 & 45 & (5.6) & 5383-H112 \\
\hline 12 & 8 & 5083-H116 & Extruded Tee & 135 & 6 & 55 & $(8.2)$ & $5383-\mathrm{H} 112$ \\
\hline 13 & 5 & 5083-H116 & Extruded Tee & 55.7 & 3.7 & 40 & $(6.7)$ & 6082-T6 \\
\hline 14 & 5 & 5083-H116 & Extruded Tee & 66.1 & 4 & 40 & $(5.7)$ & 6082-T6 \\
\hline 15 & 5 & 5083-H116 & Extruded Tee & 76.8 & 4 & 45 & $(5.6)$ & 6082-T6 \\
\hline 16 & 5 & 5083-H116 & Extruded Tee & 135 & 6 & 55 & $(8.2)$ & 6082-T6 \\
\hline 17 & 6 & 5083-H116 & Extruded Tee & 55.7 & 3.7 & 40 & $(6.7)$ & 6082-T6 \\
\hline 18 & 6 & 5083-H116 & Extruded Tee & 66.1 & 4 & 40 & $(5.7)$ & 6082-T6 \\
\hline 19 & 6 & 5083-H116 & Extruded Tee & 76.8 & 4 & 45 & (5.6) & 6082-T6 \\
\hline 20 & 6 & $5083-\mathrm{H} 116$ & Extruded Tee & 135 & 6 & 55 & $(8.2)$ & 6082-T6 \\
\hline 21 & 8 & 5083-H116 & Extruded Tee & 55.7 & 3.7 & 40 & $(6.7)$ & 6082-T6 \\
\hline 22 & 8 & 5083-H116 & Extruded Tee & 66.1 & 4 & 40 & $(5.7)$ & 6082-T6 \\
\hline 23 & 8 & 5083-H116 & Extruded Tee & 76.8 & 4 & 45 & (5.6) & 6082-T6 \\
\hline 24 & 8 & 5083-H116 & Extruded Tee & 135 & 6 & 55 & $(8.2)$ & 6082-T6 \\
\hline 25 & 5 & 5383-H116 & Extruded Tee & 55.7 & 3.7 & 40 & (6.7) & 5383-H112 \\
\hline
\end{tabular}


Table 1: Overall characteristics of the 78 prototype structures (continued)

\begin{tabular}{|c|c|c|c|c|c|c|c|c|}
\hline \multirow{2}{*}{ ID } & \multicolumn{2}{|r|}{ Plate } & \multicolumn{6}{|c|}{ Stiffener } \\
\hline & $\mathrm{t}(\mathrm{mm})$ & Alloy and temper & Type & $\mathrm{h}_{\mathrm{w}}(\mathrm{mm})$ & $\mathrm{t}_{\mathrm{w}}(\mathrm{mm})$ & $\mathrm{b}_{\mathrm{f}}(\mathrm{mm})$ & $\mathrm{t}_{\mathrm{f}}(\mathrm{mm})$ & Alloy and temper \\
\hline 26 & 5 & 5383-H116 & Extruded Tee & 66.1 & 4 & 40 & $(5.7)$ & 5383-H112 \\
\hline 27 & 5 & 5383-H116 & Extruded Tee & 76.8 & 4 & 45 & $(5.6)$ & 5383-H112 \\
\hline 28 & 5 & 5383-H116 & Extruded Tee & 135 & 6 & 55 & $(8.2)$ & 5383-H112 \\
\hline 29 & 6 & 5383-H116 & Extruded Tee & 55.7 & 3.7 & 40 & $(6.7)$ & 5383-H112 \\
\hline 30 & 6 & 5383-H116 & Extruded Tee & 66.1 & 4 & 40 & $(5.7)$ & 5383-H112 \\
\hline 31 & 6 & 5383-H116 & Extruded Tee & 76.8 & 4 & 45 & $(5.6)$ & 5383-H112 \\
\hline 32 & 6 & 5383-H116 & Extruded Tee & 135 & 6 & 55 & $(8.2)$ & 5383-H112 \\
\hline 33 & 8 & 5383-H116 & Extruded Tee & 55.7 & 3.7 & 40 & $(6.7)$ & 5383-H112 \\
\hline 34 & 8 & 5383-H116 & Extruded Tee & 66.1 & 4 & 40 & $(5.7)$ & 5383-H112 \\
\hline 35 & 8 & 5383-H116 & Extruded Tee & 76.8 & 4 & 45 & $(5.6)$ & 5383-H112 \\
\hline 36 & 8 & 5383-H116 & Extruded Tee & 135 & 6 & 55 & $(8.2)$ & 5383-H112 \\
\hline 37 & 5 & 5083-H116 & Flat & 60 & 5 & - & - & 5083-H116 \\
\hline 38 & 5 & 5083-H116 & Flat & 90 & 5 & - & - & 5083-H116 \\
\hline 39 & 5 & 5083-H116 & Flat & 120 & 5 & - & - & 5083-H116 \\
\hline 40 & 6 & 5083-H116 & Flat & 60 & 6 & - & - & 5083-H116 \\
\hline 41 & 6 & 5083-H116 & Flat & 90 & 6 & - & - & 5083-H116 \\
\hline 42 & 6 & 5083-H116 & Flat & 120 & 6 & - & - & 5083-H116 \\
\hline 43 & 8 & 5083-H116 & Flat & 60 & 8 & - & - & 5083-H116 \\
\hline 44 & 8 & 5083-H116 & Flat & 90 & 8 & - & - & 5083-H116 \\
\hline 45 & 8 & 5083-H116 & Flat & 120 & 8 & - & - & 5083-H116 \\
\hline 46 & 5 & 5083-H116 & Flat & 60 & 5 & - & - & 5383-H116 \\
\hline 47 & 5 & 5083-H116 & Flat & 90 & 5 & - & - & 5383-H116 \\
\hline 48 & 5 & 5083-H116 & Flat & 120 & 5 & - & - & 5383-H116 \\
\hline 49 & 6 & 5083-H116 & Flat & 60 & 6 & - & - & 5383-H116 \\
\hline 50 & 6 & 5083-H116 & Flat & 90 & 6 & - & - & 5383-H116 \\
\hline 51 & 6 & 5083-H116 & Flat & 120 & 6 & - & - & 5383-H116 \\
\hline 52 & 8 & 5083-H116 & Flat & 60 & 8 & - & - & 5383-H116 \\
\hline 53 & 8 & 5083-H116 & Flat & 90 & 8 & - & - & 5383-H116 \\
\hline 54 & 8 & 5083-H116 & Flat & 120 & 8 & - & - & 5383-H116 \\
\hline 55 & 5 & 5383-H116 & Flat & 60 & 5 & - & - & 5383-H116 \\
\hline 56 & 5 & 5383-H116 & Flat & 90 & 5 & - & - & 5383-H116 \\
\hline 57 & 5 & 5383-H116 & Flat & 120 & 5 & - & - & 5383-H116 \\
\hline 58 & 6 & 5383-H116 & Flat & 60 & 6 & - & - & 5383-H116 \\
\hline 59 & 6 & 5383-H116 & Flat & 90 & 6 & - & - & 5383-H116 \\
\hline 60 & 6 & 5383-H116 & Flat & 120 & 6 & - & - & 5383-H116 \\
\hline 61 & 8 & 5383-H116 & Flat & 60 & 8 & - & - & 5383-H116 \\
\hline 62 & 8 & 5383-H116 & Flat & 90 & 8 & - & - & 5383-H116 \\
\hline 63 & 8 & 5383-H116 & Flat & 120 & 8 & - & - & 5383-H116 \\
\hline
\end{tabular}


Table 1: Overall characteristics of the 78 prototype structures (continued)

\begin{tabular}{|c|c|c|c|c|c|c|c|c|}
\hline \multirow{2}{*}{ ID } & \multicolumn{2}{|c|}{ Plate } & \multicolumn{5}{c|}{ Stiffener } \\
\cline { 2 - 10 } & $\mathrm{t}(\mathrm{mm})$ & Alloy and temper & Type & $\mathrm{h}_{\mathrm{w}}(\mathrm{mm})$ & $\mathrm{t}_{\mathrm{w}}(\mathrm{mm})$ & $\mathrm{b}_{\mathrm{f}}(\mathrm{mm})$ & $\mathrm{t}_{\mathrm{f}}(\mathrm{mm})$ & Alloy and temper \\
\hline 64 & 5 & $5083-\mathrm{H} 116$ & Built-up Tee & 80 & 5 & 60 & 5 & $5083-\mathrm{H} 116$ \\
\hline 65 & 6 & $5083-\mathrm{H} 116$ & Built-up Tee & 60 & 5 & 60 & 5 & $5083-\mathrm{H} 116$ \\
\hline 66 & 8 & $5083-\mathrm{H} 116$ & Built-up Tee & 100 & 5 & 60 & 5 & $5083-\mathrm{H} 116$ \\
\hline 67 & 5 & $5083-\mathrm{H} 116$ & Built-up Tee & 80 & 5 & 60 & 5 & $5383-\mathrm{H} 116$ \\
\hline 68 & 6 & $5083-\mathrm{H} 116$ & Built-up Tee & 60 & 5 & 60 & 5 & $5383-\mathrm{H} 116$ \\
\hline 69 & 8 & $5083-\mathrm{H} 116$ & Built-up Tee & 100 & 5 & 60 & 5 & $5383-\mathrm{H} 116$ \\
\hline 70 & 5 & $5383-\mathrm{H} 116$ & Built-up Tee & 80 & 5 & 60 & 5 & $5383-\mathrm{H} 116$ \\
\hline 71 & 6 & $5383-\mathrm{H} 116$ & Built-up Tee & 60 & 5 & 60 & 5 & $5383-\mathrm{H} 116$ \\
\hline 72 & 8 & $5383-\mathrm{H} 116$ & Built-up Tee & 100 & 5 & 60 & 5 & $5383-\mathrm{H} 116$ \\
\hline
\end{tabular}

One bay test plate structures $(1000 \mathrm{~mm} \times 1000 \mathrm{~mm})$ :

\begin{tabular}{|c|c|c|c|c|c|c|c|c|}
\hline \multirow{2}{*}{ ID } & \multicolumn{3}{|c|}{ Plate } & \multicolumn{5}{c|}{ Stiffener } \\
\cline { 2 - 10 } & $\mathrm{t}(\mathrm{mm})$ & Alloy and temper & Type & $\mathrm{h}_{\mathrm{w}}(\mathrm{mm})$ & $\mathrm{t}_{\mathrm{w}}(\mathrm{mm})$ & $\mathrm{b}_{\mathrm{f}}(\mathrm{mm})$ & $\mathrm{t}_{\mathrm{f}}(\mathrm{mm})$ & Alloy and temper \\
\hline 73 & 6 & $5083-\mathrm{H} 116$ & Extruded Tee & 76.8 & 4 & 45 & $(5.6)$ & $6082-\mathrm{T} 6$ \\
\hline 74 & 8 & $5083-\mathrm{H} 116$ & Extruded Tee & 100 & 6 & 55 & $(8.2)$ & $6082-\mathrm{T} 6$ \\
\hline 75 & 8 & $5383-\mathrm{H} 116$ & Extruded Tee & 100 & 6 & 55 & $(8.2)$ & $5383-\mathrm{H} 112$ \\
\hline
\end{tabular}

Three bay test plate structures $(3000 \mathrm{~mm} \times 1000 \mathrm{~mm})$ :

\begin{tabular}{|c|c|c|c|c|c|c|c|c|}
\hline \multirow{2}{*}{ ID } & \multicolumn{3}{|c|}{ Plate } & \multicolumn{5}{c|}{ Stiffener } \\
\cline { 2 - 10 } & $\mathrm{t}(\mathrm{mm})$ & Alloy and temper & Type & $\mathrm{h}_{\mathrm{w}}(\mathrm{mm})$ & $\mathrm{t}_{\mathrm{w}}(\mathrm{mm})$ & $\mathrm{b}_{\mathrm{f}}(\mathrm{mm})$ & $\mathrm{t}_{\mathrm{f}}(\mathrm{mm})$ & Alloy and temper \\
\hline 76 & 6 & $5083-\mathrm{H} 116$ & Extruded Tee & 76.8 & 4 & 45 & $(5.6)$ & $6082-\mathrm{T} 6$ \\
\hline 77 & 8 & $5083-\mathrm{H} 116$ & Extruded Tee & 100 & 6 & 55 & $(8.2)$ & $6082-\mathrm{T} 6$ \\
\hline 78 & 8 & $5383-\mathrm{H} 116$ & Extruded Tee & 100 & 6 & 55 & $(8.2)$ & $5383-\mathrm{H} 112$ \\
\hline
\end{tabular}

Notes: $\mathrm{t}=$ plate thickness, $\mathrm{h}_{\mathrm{w}}=$ web height (excluding flange thickness), $\mathrm{t}_{\mathrm{w}}=$ web thickness, $\mathrm{b}_{\mathrm{f}}=$ flange width, $\mathrm{t}_{\mathrm{f}}=$ flange thickness, $\mathrm{t}_{\mathrm{f}}$ where given in brackets indicates the effective value of for an idealized plate-stiffener combination with the same moment of inertia as the actual case.

Table 2: Minimum values of mechanical properties of aluminum alloys used for the construction of prototype structures (DNV 2003)

\begin{tabular}{|c|c|c|c|c|c|}
\hline $\begin{array}{c}\text { Alloy and } \\
\text { temper }\end{array}$ & $\begin{array}{c}\text { Yield strength of } \\
\text { base metal } \\
\left(\mathrm{N} / \mathrm{mm}^{2}\right)\end{array}$ & $\begin{array}{c}\text { Tensile strength } \\
\text { of base metal } \\
\left(\mathrm{N} / \mathrm{mm}^{2}\right)\end{array}$ & $\begin{array}{c}\text { Elongation of } \\
\text { base metal }(\%)\end{array}$ & $\begin{array}{c}\text { Type of } \\
\text { production }\end{array}$ & $\begin{array}{c}\text { Yield strength of } \\
\text { welded material } \\
\left(\mathrm{N} / \mathrm{mm}^{2}\right)\end{array}$ \\
\hline $5083-\mathrm{H} 116$ & 215 & 305 & 10 & Rolled & Rolled \\
\hline $5383-\mathrm{H} 116$ & 220 & 305 & 10 & Extruded \\
\hline $5383-\mathrm{H} 112$ & 190 & 310 & 13 & Extruded & 145 \\
\hline $6082-\mathrm{T6}$ & 240 & 290 & 5 & 100 \\
\hline
\end{tabular}

Note: Elastic modulus $\mathrm{E}=70,000 \mathrm{~N} / \mathrm{mm}^{2}$, Poisson's ratio $v=0.33$. 
Table 3: Summary of the ultimate strengths of test structures together with collapse modes obtained by FEA and experiment

\begin{tabular}{|c|c|c|c|c|c|c|c|c|c|c|}
\hline \multirow{3}{*}{ ID } & \multirow{2}{*}{\multicolumn{2}{|c|}{ Exp. }} & \multicolumn{8}{|c|}{ FEA } \\
\hline & & & \multicolumn{2}{|c|}{1 bay-CIP } & \multicolumn{2}{|c|}{1 bay-CIS } & \multicolumn{2}{|c|}{2 bay-CIS } & \multicolumn{2}{|c|}{2 bay-CIS } \\
\hline & $\sigma_{\mathrm{u}} / \sigma_{\mathrm{Yeq}}$ & Mode & $\sigma_{\mathrm{u}} / \sigma_{\mathrm{Yeq}}$ & Mode & $\sigma_{\mathrm{u}} / \sigma_{\mathrm{Yeq}}$ & Mode & $\sigma_{\mathrm{u}} / \sigma_{\mathrm{Yeq}}$ & Mode & $\sigma_{\mathrm{u}} / \sigma_{\mathrm{Yeq}}$ & Mode \\
\hline ID1 & 0.462 & III & 0.380 & III & 0.413 & III & 0.474 & III & 0.449 & V \\
\hline ID2 & 0.487 & V & 0.426 & III & 0.459 & III & 0.508 & III & 0.471 & V \\
\hline ID3 & 0.517 & III , IV & 0.460 & III & 0.490 & III & 0.517 & III & 0.492 & V \\
\hline ID4 & 0.546 & IV,V & 0.452 & III & 0.456 & III & 0.550 & $\mathrm{~V}$ & 0.562 & V \\
\hline ID5 & 0.448 & III & 0.434 & III & 0.482 & III & 0.478 & III & 0.471 & V \\
\hline ID6 & 0.530 & III & 0.490 & III & 0.536 & III & 0.516 & III & 0.495 & V \\
\hline ID7 & 0.516 & III & 0.521 & III & 0.559 & III & 0.554 & III & 0.526 & V \\
\hline ID8 & 0.615 & V & 0.554 & III & 0.560 & III & 0.604 & V & 0.590 & V \\
\hline ID9 & 0.531 & V & 0.459 & III & 0.421 & V & 0.485 & III & 0.491 & V \\
\hline ID10 & 0.407 & V & 0.568 & V & 0.417 & V & 0.533 & III & 0.534 & V \\
\hline ID11 & 0.526 & V & 0.589 & V & 0.467 & V & 0.590 & III & 0.581 & V \\
\hline ID12 & 0.557 & V & 0.673 & III & 0.692 & III & 0.670 & V & 0.650 & V \\
\hline ID13 & 0.435 & III & 0.354 & III & 0.390 & III & 0.491 & III & 0.474 & V \\
\hline ID14 & 0.477 & III & 0.399 & III & 0.434 & III & 0.531 & III & 0.479 & V \\
\hline ID15 & 0.492 & III ,IV & 0.433 & III & 0.464 & III & 0.602 & III & 0.543 & V \\
\hline ID16 & 0.596 & III ,IV & 0.505 & III & 0.511 & III & 0.582 & V & 0.593 & V \\
\hline ID17 & 0.431 & III & 0.402 & III & 0.452 & III & 0.506 & III & 0.491 & V \\
\hline ID18 & 0.460 & III & 0.458 & III & 0.528 & III & 0.532 & III & 0.500 & V \\
\hline ID19 & 0.513 & III ,IV & 0.487 & III & 0.529 & III & 0.602 & III & 0.556 & V \\
\hline ID20 & 0.627 & III ,IV & 0.503 & III & 0.514 & III & 0.575 & V & 0.582 & V \\
\hline ID21 & 0.525 & III & 0.501 & III & 0.468 & V & 0.521 & III & 0.533 & V \\
\hline ID22 & 0.610 & V & 0.590 & III & 0.451 & V & 0.570 & III & 0.570 & V \\
\hline ID23 & 0.651 & $\mathrm{IV}, \mathrm{V}$ & 0.622 & III & 0.514 & V & 0.662 & III & 0.647 & V \\
\hline ID24 & 0.613 & III , IV & 0.614 & III & 0.645 & III & 0.674 & V & 0.687 & V \\
\hline ID25 & 0.384 & III & 0.383 & III & 0.419 & III & 0.468 & III & 0.442 & V \\
\hline ID26 & 0.418 & III & 0.430 & III & 0.464 & III & 0.501 & III & 0.464 & V \\
\hline ID27 & 0.448 & III ,IV & 0.464 & III & 0.494 & III & 0.564 & III & 0.497 & V \\
\hline ID28 & 0.549 & III , IV & 0.513 & III & 0.544 & III & 0.577 & V & 0.570 & V \\
\hline ID29 & 0.447 & V & 0.433 & III & 0.485 & III & 0.486 & III & 0.475 & V \\
\hline ID30 & 0.515 & V & 0.488 & III & 0.537 & III & 0.532 & III & 0.508 & V \\
\hline ID31 & 0.494 & III ,IV & 0.525 & III & 0.564 & III & 0.564 & III & 0.543 & V \\
\hline ID32 & 0.548 & III , IV & 0.552 & III & 0.590 & III & 0.608 & V & 0.594 & V \\
\hline ID33 & 0.544 & V & 0.518 & III & 0.407 & $\mathrm{~V}$ & 0.551 & III & 0.538 & V \\
\hline ID34 & 0.538 & V & 0.536 & III & 0.401 & V & 0.575 & III & 0.564 & V \\
\hline ID35 & 0.491 & V & 0.564 & V & 0.448 & V & 0.612 & III & 0.600 & V \\
\hline
\end{tabular}




\begin{tabular}{|c|c|c|c|c|c|c|c|c|c|c|}
\hline & \multicolumn{1}{|c|}{} & \multicolumn{7}{|c|}{ FEA } \\
\hline ID36 & 0.516 & V & 0.602 & III & 0.628 & III & 0.664 & V & 0.645 & V \\
\hline ID37 & 0.356 & III & 0.312 & III & 0.339 & III & 0.361 & III & 0.384 & V \\
\hline ID38 & 0.512 & III & 0.471 & III & 0.460 & V & 0.513 & III & 0.510 & V \\
\hline ID39 & 0.416 & V & 0.406 & III & 0.393 & V & 0.423 & III & 0.418 & V \\
\hline ID40 & 0.301 & III & 0.290 & III & 0.304 & III & 0.312 & III & 0.326 & V \\
\hline ID41 & 0.463 & III & 0.457 & III & 0.465 & III & 0.523 & III & 0.482 & V \\
\hline ID42 & 0.430 & V & 0.427 & III & 0.413 & V & 0.465 & III & 0.440 & V \\
\hline
\end{tabular}

Table 3: Summary of the ultimate strengths of test structures together with collapse modes obtained by FEA and experiment (continued)

\begin{tabular}{|c|c|c|c|c|c|c|c|c|c|c|}
\hline \multirow{3}{*}{ ID } & \multirow{2}{*}{\multicolumn{2}{|c|}{ Exp. }} & \multicolumn{8}{|c|}{ FEA } \\
\hline & & & \multicolumn{2}{|c|}{1 bay-CIP } & \multicolumn{2}{|c|}{1 bay-CIS } & \multicolumn{2}{|c|}{2 bay-CIS } & \multicolumn{2}{|c|}{2 bay-CIS } \\
\hline & $\sigma_{\mathrm{u}} / \sigma_{\mathrm{Yeq}}$ & Mode & $\sigma_{\mathrm{u}} / \sigma_{\mathrm{Yeq}}$ & Mode & $\sigma_{\mathrm{u}} / \sigma_{\mathrm{Yeq}}$ & Mode & $\sigma_{\mathrm{u}} / \sigma_{\mathrm{Yeq}}$ & Mode & $\sigma_{\mathrm{u}} / \sigma_{\mathrm{Yeq}}$ & Mode \\
\hline ID43 & 0.325 & V & 0.318 & III & 0.329 & V & 0.343 & III & 0.355 & V \\
\hline ID44 & 0.553 & V & 0.543 & III & 0.570 & III & 0.577 & III & 0.566 & V \\
\hline ID45 & 0.556 & V & 0.520 & III & 0.560 & V & 0.588 & III & 0.558 & V \\
\hline ID46 & 0.357 & III & 0.313 & III & 0.341 & III & 0.353 & III & 0.377 & V \\
\hline ID47 & 0.504 & V & 0.472 & III & 0.483 & V & 0.514 & III & 0.516 & V \\
\hline ID48 & 0.319 & V & 0.284 & III & 0.281 & V & 0.344 & III & 0.358 & V \\
\hline ID49 & 0.271 & III & 0.264 & III & 0.288 & III & 0.314 & III & 0.327 & $\mathrm{~V}$ \\
\hline ID50 & 0.559 & V & 0.522 & III & 0.545 & V & 0.567 & III & 0.569 & V \\
\hline ID51 & 0.513 & V & 0.507 & III & 0.484 & V & 0.530 & III & 0.495 & V \\
\hline ID52 & 0.394 & III & 0.413 & III & 0.418 & V & 0.451 & III & 0.449 & V \\
\hline ID53 & 0.572 & III & 0.572 & III & 0.559 & III & 0.581 & III & 0.583 & V \\
\hline ID54 & 0.506 & V & 0.493 & III & 0.486 & V & 0.560 & III & 0.511 & V \\
\hline ID55 & 0.323 & III & 0.295 & III & 0.315 & III & 0.332 & III & 0.343 & V \\
\hline ID56 & 0.467 & V & 0.440 & III & 0.411 & V & 0.476 & III & 0.450 & V \\
\hline ID57 & 0.386 & V & 0.369 & III & 0.349 & V & 0.425 & III & 0.410 & V \\
\hline ID58 & 0.312 & III & 0.292 & III & 0.306 & III & 0.312 & III & 0.324 & V \\
\hline ID59 & 0.432 & III & 0.436 & III & 0.446 & III & 0.472 & III & 0.447 & V \\
\hline ID60 & 0.419 & V & 0.435 & III & 0.389 & V & 0.402 & III & 0.422 & V \\
\hline ID61 & 0.405 & III & 0.385 & III & 0.380 & V & 0.397 & III & 0.405 & V \\
\hline ID62 & 0.687 & V & 0.575 & III & 0.635 & III & 0.616 & III & 0.621 & V \\
\hline ID63 & 0.561 & V & 0.570 & III & 0.556 & V & 0.579 & III & 0.558 & V \\
\hline ID64 & 0.518 & III , IV & 0.465 & III & 0.500 & III & 0.567 & III & 0.522 & V \\
\hline ID65 & 0.508 & III & 0.468 & III & 0.500 & III & 0.510 & III & 0.486 & V \\
\hline ID66 & 0.579 & V & 0.612 & III & 0.545 & V & 0.612 & III & 0.619 & V \\
\hline ID67 & 0.526 & III , IV & 0.464 & III & 0.520 & III & 0.579 & III & 0.523 & V \\
\hline ID68 & 0.466 & III , IV & 0.467 & III & 0.523 & III & 0.510 & III & 0.487 & $\mathrm{~V}$ \\
\hline ID69 & 0.501 & V & 0.617 & III & 0.560 & V & 0.625 & III & 0.621 & V \\
\hline
\end{tabular}




\begin{tabular}{|c|c|c|c|c|c|c|c|c|c|c|}
\hline & & & \multicolumn{8}{|c|}{ FEA } \\
\hline ID70 & 0.485 & III , IV & 0.469 & III & 0.502 & III & 0.574 & III & 0.517 & V \\
\hline ID71 & 0.460 & III & 0.472 & III & 0.531 & III & 0.505 & III & 0.480 & V \\
\hline ID72 & 0.619 & V & 0.633 & III & 0.547 & V & 0.619 & III & 0.614 & V \\
\hline ID73 & 0.526 & III & 0.520 & III & 0.554 & III & - & - & - & - \\
\hline ID74 & 0.589 & III ,IV & 0.603 & III & 0.644 & III & - & - & - & - \\
\hline ID75 & 0.592 & III ,IV & 0.612 & III & 0.651 & III & - & - & - & - \\
\hline ID76 & 0.529 & III & - & - & - & - & 0.564 & III & 0.541 & V \\
\hline ID77 & 0.563 & III ,IV & - & - & - & - & 0.581 & III & 0.557 & V \\
\hline ID78 & 0.607 & III & - & - & - & - & 0.643 & III & 0.620 & V \\
\hline
\end{tabular}

